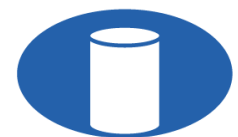

IBRACON Structures and Materials Journal

Revista IBRACON de Estruturas e Materiais

IBRACON

ISSN 1983-4195

ismj.org

ORIGINAL ARTICLE

\title{
Assessment of the effect of changes in consolidation conditions in the advance of the carbonation front in cementitious matrix composites
}

\section{Avaliação do efeito da alteração nas condições de adensamento no avanço da frente de carbonatação em compósitos de matriz cimentícia}

\author{
Ruan Gustavo Rezende Silva ${ }^{a}$ (D) \\ Aldo Giuntini de Magalhães ${ }^{\mathrm{a}}$ (ii) \\ Christopher Augusto Campos ${ }^{\mathrm{a}}$ (D) \\ Ivair Ramos Silva ${ }^{\mathrm{b}}$ (D)
}

\begin{abstract}
${ }^{a}$ Universidade Federal de Minas Gerais - UFMG, Escola de Engenharia, Departamento de Engenharia de Materiais e Construção Civil, Belo Horizonte, MG, Brasil

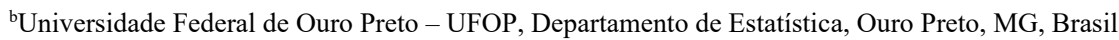

Received 11 June 2020

Accepted 07 January 2021

\begin{abstract}
Carbonation is one of the main deleterious effects of reinforced concrete structures, as it creates a favorable condition for the reinforcement depassivation and, thus, facilitates the onset of the corrosive process. The phenomenon is directly influenced by the material void's structure, which is affected by the consolidation of the mass in the fresh state, subject evaluated in this study. For this purpose, samples were made using two water to cement ratios and defining two different consolidation methods. Compressive strength tests were carried out for the mechanical characterization of the specimens, in addition to accelerated carbonation tests, monitoring the progress of the carbonated thickness using the phenolphthalein colorimetric indicator, during 98 days. Microstructural differences were evaluated by scanning electron microscopy (SEM). The results indicate that the lower the workability of the mixture, the greater the impacts on the compressive strength of the material, resulting from failures in the consolidation stage. Nevertheless, another behavior is observed when evaluating this effect in the advancement of the carbonation front, indicating that the voids structure of the material should not be evaluated only according to its volume, but also in terms of the pattern of its distribution, its morphology and its connectivity.
\end{abstract}

Keywords: cementitious composites, durability, carbonation, consolidation

Resumo: A carbonatação é um dos principais efeitos deletérios das estruturas de concreto armado, por criar uma condição favorável à despassivação das armaduras e, assim, facilitar o início do processo corrosivo. $\mathrm{O}$ fenômeno é diretamente influenciado pela estrutura de vazios do material que, por sua vez, é afetada pelo adensamento da massa no estado fresco, variável avaliada nesse trabalho. Para tanto, foram moldados corpos de prova utilizando-se duas relações água/cimento e definindo-se dois padrões distintos de compactação das misturas. Foram realizados ensaios de resistência à compressão, para caracterização mecânica das amostras, e ensaios de carbonatação acelerada, fazendo-se o acompanhamento do avanço da espessura carbonatada por meio do indicador colorimétrico de fenolftaleína, durante 98 dias. Diferenças microestruturais foram avaliadas por meio de microscopia eletrônica de varredura (MEV). Os resultados indicam que quanto menor a trabalhabilidade da mistura, maiores serão os impactos na resistência à compressão do material, decorrentes de falhas na etapa de adensamento. Apesar disso, outro comportamento é observado ao avaliar esse efeito no avanço da frente de carbonatação, indicando que a estrutura de vazios do material não deve ser avaliada apenas em função do seu volume, mas também quanto ao padrão de sua distribuição, sua morfologia e conectividade.

Palavras-chave: compósitos cimentícios, durabilidade, carbonatação, adensamento.

Corresponding author: Aldo Giuntini de Magalhães. E-mail: aldom@ufmg.br

Financial support: None.

Conflict of interest: Nothing to declare. 
How to cite: R. G. R. Silva, A. G. Magalhães, C. A. Campos, and I. R. Silva, "Assessment of the effect of changes in consolidation conditions in the advance of the carbonation front in cementitious matrix composites," Rev. IBRACON Estrut. Mater., vol. 14, no. 5, e14512, 2021, https://doi.org/10.1590/S1983-41952021000500012

\section{INTRODUCTION}

An important factor to be considered while designing reinforced concrete structures projects is their expected life span. Normative requirements, such as the maximum water/cement ratio to be used in the mixture, the minimum cover of the reinforcement and the minimum consumption of cement, are prescribed according to a certain class of environmental aggressiveness, aiming to guarantee their durability. These criteria aim to control the flow of fluids through the concrete void structure, preventing its degradation by aggressive external agents, such as chlorides, sulfates and acid gases.

According to Figueiredo [1] and Cascudo and Carasek [2], the main acid gases present in the atmosphere in contact with the surface of the structural elements are carbon dioxide $\left(\mathrm{CO}_{2}\right)$, sulfur dioxide $\left(\mathrm{SO}_{2}\right)$ and hydrogen sulfide $\left(\mathrm{H}_{2} \mathrm{~S}\right)$, responsible for neutralizing the $\mathrm{pH}$ of the composite interstitial liquid phase, in a process known as carbonation or neutralization of concrete [3]. As a result of this phenomenon, concrete, which initially is a very alkaline medium, with a pH close to 13, can reach $\mathrm{pH}$ values between 8 and 9 [4], [5].

After its diffusion and dissolution in the liquid phase present in the pores of the cement matrix composite, $\mathrm{CO}_{2}$ reacts with the products of the dissolution of calcium hydroxide $\left[\mathrm{Ca}(\mathrm{OH})_{2}\right]$, from the hydration of cement, forming calcium carbonate $\left(\mathrm{CaCO}_{3}\right)$. Carbonation can also happen with the participation of other compounds, such as calcium silicate hydrate $(\mathrm{CSH})$ and with non-hydrated silicates: tricalcium silicate $\left(\mathrm{C}_{3} \mathrm{~S}\right)$ and dicalcium silicate $\left(\mathrm{C}_{2} \mathrm{~S}\right)[5]-[7]$.

The carbonation front advances from the surface to the interior of the structure and, upon reaching the reinforced concrete, causes its depassivation, leaving it susceptible to corrosion. According to Cascudo and Carasek [2] and Neville [8], the $\mathrm{pH}$ range below which the passivation layer cannot be maintained is between 11.5 and 11.8, whereas favorable conditions for triggering the corrosion of the steel occur when its $\mathrm{pH}$ drops below a limit value around 9 [9]. Since the first studies carried out by Hamada [3], Meyer [10] and other contemporaries, still in the 1960s, carbonation is considered by the entire technical-scientific community as one of the main harmful effects of reinforced concrete structures, due to the creation of favorable conditions for steel corrosion to start.

Carbonation is a slow process, whose forward velocity decreases with time, a fact, due to the lasting process of hydration of Portland cement and the reduction of concrete permeability, since the formed carbonates lead to clogging of the pores, making it difficult for the $\mathrm{CO}_{2}$ to pass. Although there are complex models that seek to estimate carbonated depth as time-related, a well-known and accepted model is represented by Equation 1, derived from Fick's First Law of Diffusion.

$e_{\mathrm{CO}_{2}}=k \cdot \sqrt{t}$

where $\mathrm{e}_{\mathrm{CO} 2}$ is the carbonated thickness, $k$ is a carbonation coefficient, related to $\mathrm{CO}_{2}$ diffusivity, and $t$ is the exposure time.

The $\mathrm{k}$ coefficient and, therefore, the speed of $\mathrm{CO}_{2}$ penetration, is influenced both by external factors related to the exposure conditions, such as the $\mathrm{CO}_{2}$ content of the environment, the relative humidity and the temperature, as well as the characteristics of the cementitious composite, such as, for example, the water/cement ratio of the mixture, the mass consolidation in the fresh state, the presence of additives and admixtures and the consumption and type of cement. Such parameters are capable of producing variations, alone or together, in the $\mathrm{pH}$ value (alkaline reserve) of the composite and in the formed pore system.

According to Neville and Brooks [11], the voids present in the hardened concrete are composed of bubbles of trapped air or spaces left by the mass excess water outlet. The trapped air can be removed during the stage of concrete consolidation in the fresh state, while the space left by the water outlet is directly related to the water/cement ratio of the mixture. By reducing voids, concrete becomes denser and less permeable, and, consequently, more resistant and durable.

According to ACI 309R-05 [12], the consolidation must be compatible with the mixture and with the conditions of the structural element being produced. The guide presents manual and mechanical methods for carrying out consolidation, mentioning, for example, the use of rods and vibration, and highlights that in certain situations it may be necessary to combine more than one of these alternatives. Not only consolidation lack, but also excess, presents itself as a problem, either due to the prolonged time or the high energy used. Al-Khalaf and Yousif [13] evaluated the impact of the degree of compaction of the 
mixture, represented by the vibration time, on the compressive strength of concrete specimens and concluded that there is an optimum time that leads to the greatest resistance. Short compaction times lead to voids in the material and longer times cause instability in the mixture due to excessive vibration, and both effects are responsible for decreases in resistance.

Gonen and Yazicioglu [14], working with samples with different porosity levels, generated by variations in the stage of consolidation of the mixtures, observed a reduction of the mechanical resistance and an increase of the carbonation depth in the samples with worse levels of consolidation (greater porosities). Besides that, they observed that even a small compaction of the mass can promote an increase in the compressive strength and that the consolidation is more important in terms of durability. Gao et al. [15], using chloride ion permeability tests, found a decrease in the long-term durability of cementitious composites caused by excessive consolidation. The authors found that this excess causes the segregation of the mixture components and facilitates the entry of aggressive agents.

Despite being an important step for the material to achieve the expected performance, there are few studies in the literature that specifically evaluate this step and that quantify the impact of this variable on the properties of cementitious composites. In view of this, the present work evaluated the influence of the consolidation and the water/cement ratio $(\mathrm{w} / \mathrm{c})$ of the mixture in the advance of the carbonation front.

\section{MATERIALS AND METHODS}

The present study was carried out in cylindrical mortar specimens of dimensions $(5 \times 10) \mathrm{cm}$, molded using Portland cement CPV-ARI (High Initial Resistance), potable water and four granulometric fractions of sand, following the mixing procedures described in NBR 7215 [16]. Two water/cement ratios were used to mold the specimens, with two consolidation patterns being defined for each of them, for further evaluation of the effect caused in the advance of the carbonation front.

For statistical analysis of the data generated with the experiment, two-way analysis of variance (ANOVA) and the Tukey's MSD multiple comparison method were used.

\section{Cement}

Portland cement of high initial strength (CPV-ARI) was used due to its lower number of supplementary cementitious materials, since the replacement of clinker by carbonate material is limited to $10 \%$ by NBR 16697 [17], reducing the number of variables that could cause changes in the results obtained. The physical and chemical characterizations of the cement used can be seen in Tables 1 and 2 .

Table 1. Physical characterizations of the cement used.

\begin{tabular}{|c|c|c|c|}
\hline \multicolumn{2}{|l|}{ Test } & Results & Limits NBR 16697 [17] \\
\hline \multicolumn{2}{|c|}{ Fineness/Surface area $\left(\mathrm{cm}^{2} / \mathrm{g}\right)$} & 4767 & $\geq 3000$ \\
\hline \multicolumn{2}{|c|}{ Initial setting time (min) } & 121 & $\geq 60$ \\
\hline \multicolumn{2}{|c|}{ Final setting time $(\mathrm{min})$} & 176 & $\leq 600$ \\
\hline \multirow{4}{*}{ Compressive strength (MPa) } & 1 day & 29.2 & $\geq 14.0$ \\
\hline & 3 days & 41.4 & $\geq 24.0$ \\
\hline & 7 days & 46.1 & $\geq 34.0$ \\
\hline & 28 days & 54.4 & - \\
\hline
\end{tabular}

Table 2. Chemical characterizations of the cement used.

\begin{tabular}{cccc}
\hline Chemical determination & Normative Reference & Cement used (\%) & $\begin{array}{c}\text { Limits NBR 16697 [17] } \\
\text { (\%) }\end{array}$ \\
\hline Calcium oxide $(\mathrm{CaO})$ & NBR 14656 & - & - \\
\hline Silicon Oxide $\left(\mathrm{SiO}_{2}\right)$ & NBR 14656 & 63.83 & - \\
\hline Aluminum Oxide $\left(\mathrm{Al}_{2} \mathrm{O}_{3}\right)$ & NBR 14656 & 19.19 & - \\
\hline Iron oxide $\left(\mathrm{Fe}_{2} \mathrm{O}_{3}\right)$ & NBR 14656 & 4.91 & $\leq 6.5$ \\
\hline Magnesium oxide $(\mathrm{MgO})$ & NBR 14656 & 3.03 & $\leq 4.5$ \\
\hline Sulfur Trioxide $\left(\mathrm{SO}_{3}\right)$ & NBR 14656 & 0.71 & $\leq 5.5$ \\
\hline Carbon dioxide $\left(\mathrm{CO}_{2}\right)$ & NBR NM 20 & - \\
\hline Potassium oxide $\left(\mathrm{K}_{2} \mathrm{O}\right)$ & NBR 14656 & 2.97 & $\leq 6.5$ \\
\hline Loss on ignition $1000{ }^{\circ} \mathrm{C}(\mathrm{PF})$ & NBR NM 18 & 0.73 & $\leq 3.5$ \\
\hline Insoluble residue $(\mathrm{RI})$ & NBR NM 15 & 3.92 & 0.97 \\
\hline
\end{tabular}




\section{Sands}

The sand used in the manufacture of the tested specimens was supplied by the São Paulo Institute of Technological Research (IPT), meeting the criteria established by NBR 7214 [18], being divided into four granulometric fractions (coarse, medium coarse, medium fine and fine).

\section{Preparation of the specimens}

The cement matrix composites used in the tests were produced taking as a reference the recommendations specified in NBR 7215 [16]. The amount of water, defined for each of the mixtures, varied according to the maximum water/cement ratio expected for the environmental aggressiveness classes I and III established in NBR 6118 [19]. The quantities of materials used in each mortar can be seen in Table 3.

Table 3. Quantity of materials in each mixture.

\begin{tabular}{ccc}
\hline Material & \multicolumn{2}{c}{ Mixing mass $(\mathbf{g})$} \\
\cline { 2 - 3 } & w/c ratio $=\mathbf{0 . 5 5}$ & w/c ratio $=\mathbf{0 . 6 5}$ \\
\hline Cement Portland CPV-ARI & $624.0 \pm 0.4$ & $624.0 \pm 0.4$ \\
\hline Water & $343.2 \pm 0.2$ & $405.6 \pm 0.2$ \\
\hline Coarse fraction sand & $468.0 \pm 0.3$ & $468.0 \pm 0.3$ \\
\hline Medium coarse fraction sand & $468.0 \pm 0.3$ & $468.0 \pm 0.3$ \\
\hline Medium fine fraction sand & $468.0 \pm 0.3$ & $468.0 \pm 0.3$ \\
\hline Fine fraction sand & $468.0 \pm 0.3$ & $468.0 \pm 0.3$ \\
\hline
\end{tabular}

Initially, the normal consistency index of the mortars used in this work was determined, according to the procedures described in Annex B of NBR 7215 [16]. For each water/cement ratio adopted, the workability of the mass in the fresh state was determined, in order to verify the influence of water in the mixture and adapt the molding procedures for each one.

The filling of the forms and the consolidation of the mass was carried out in two different ways for each of the mixtures produced, in order to evaluate its effect on the advance of the carbonation front. The variation in the consistency of the mixtures, obtained according to the variation in the water/cement ratio used, caused different procedures to be used for each mixture.

For the mixtures produced with a w/c ratio equal to 0.55 , half of the molded specimens were compacted on a vibrating table, filling the form in two layers, using 15 seconds of vibration for the first layer and 5 seconds for the second (pattern A). The other half was consolidated by the impact of a rubber hammer on the side of the mold, with filling also in two layers, with 3 blows on the side for the first layer and 2 blows for the second (pattern B).

Likewise, half of the specimens molded with the mixture produced with the w/c ratio equal to 0.65 were compacted on a vibrating table, with two layers of filling. In this case, however, 7 seconds of vibration were applied to the first layer and 3 seconds to the second (pattern $\mathrm{C}$ ). The other half was consolidated by the impact of a rubber hammer, the filling, this time, being made in a single layer, being applied 3 blows in the completely filled form (pattern D).

Table 4 presents the information related to each consolidation pattern. It was tried, through standards A and $\mathrm{C}$, to produce a better consolidation condition than standards B and D, which were purposely defined to evaluate the influence of this variable in the process of advancing the carbonation front of cementitious composites analyzed.

Table 4. Consolidation patterns used.

\begin{tabular}{cccccc}
\hline w/c ratio & $\begin{array}{c}\text { Consolidation } \\
\text { pattern }\end{array}$ & $\begin{array}{c}\text { Number of } \\
\text { layers }\end{array}$ & Consolidation type & \multicolumn{2}{c}{ Vibration time / Number of blows } \\
\cline { 2 - 6 } 0.55 & A & 2 & Vibration & $\mathbf{1}^{\mathbf{a}}$ layer & $\mathbf{2}^{\mathbf{a}}$ layer \\
\hline \multirow{2}{*}{0.65} & $\mathrm{~B}$ & 2 & Blows & 3 seconds & 5 seconds \\
& $\mathrm{C}$ & 2 & Vibration & 7 seconds & 2 blows \\
\hline
\end{tabular}


After deformation, the specimens were submitted to a curing stage. To determine the compressive strength, the specimens were submerged in water saturated with lime until the date of the test, as recommended by NBR 7215 [16]. In the case of the accelerated carbonation test, the specimens were submerged in water for a period of 28 days, as recommended by ISO 1920-12 [20].

For each test, corresponding to a dosing and consolidation condition, three cylindrical specimens were molded, in dimensions $(5 \times 10) \mathrm{cm}$. The evaluation of the advance of the carbonation front in the samples was carried out at the ages of $0,28,56,70$ and 98 days. The evaluation of the compressive strength of specimens was performed at the ages of 3,7 and 28 days.

\section{Preconditioning conditions}

Preconditioning was carried out at a stage subsequent to curing, where the specimens were subjected to procedures that sought to regulate their moisture before being stored in the carbonation chamber. It is an important step, because if this regularization is not done, the samples can start the accelerated carbonation process under different saturation conditions, thus causing undue changes in the results due to the different times that each one would take to reach balance with pre-established conditions inside the chamber [4], [21].

In previous studies, a reduction in the superficial alkalinity of the specimens kept in contact with air for short periods of time was observed [22]. Thus, an attempt was made to establish a procedure for the preconditioning step that would avoid exposing the specimens to the air, after the end of the submerged cure.

The preconditioning adopted in this work, carried out over 7 days, was divided into two stages. The first step consisted of drying the samples in a vacuum oven, with an internal temperature adjusted to $35^{\circ} \mathrm{C}$, for 5 days. In this period there was a reduction in the humidity of the specimens to levels close to those defined for the storage of the same in the carbonation chamber, without remaining in contact with gases of any nature. Subsequently, in a second stage, the samples were packaged and kept in plastic film for a further 2 days in a laboratory environment, so that a more uniform distribution of moisture would occur in its interior.

In this way, the preconditioning used prevented the onset of uncontrolled carbonation in the specimens, before entering the chamber for the accelerated carbonation test (Figure 1).
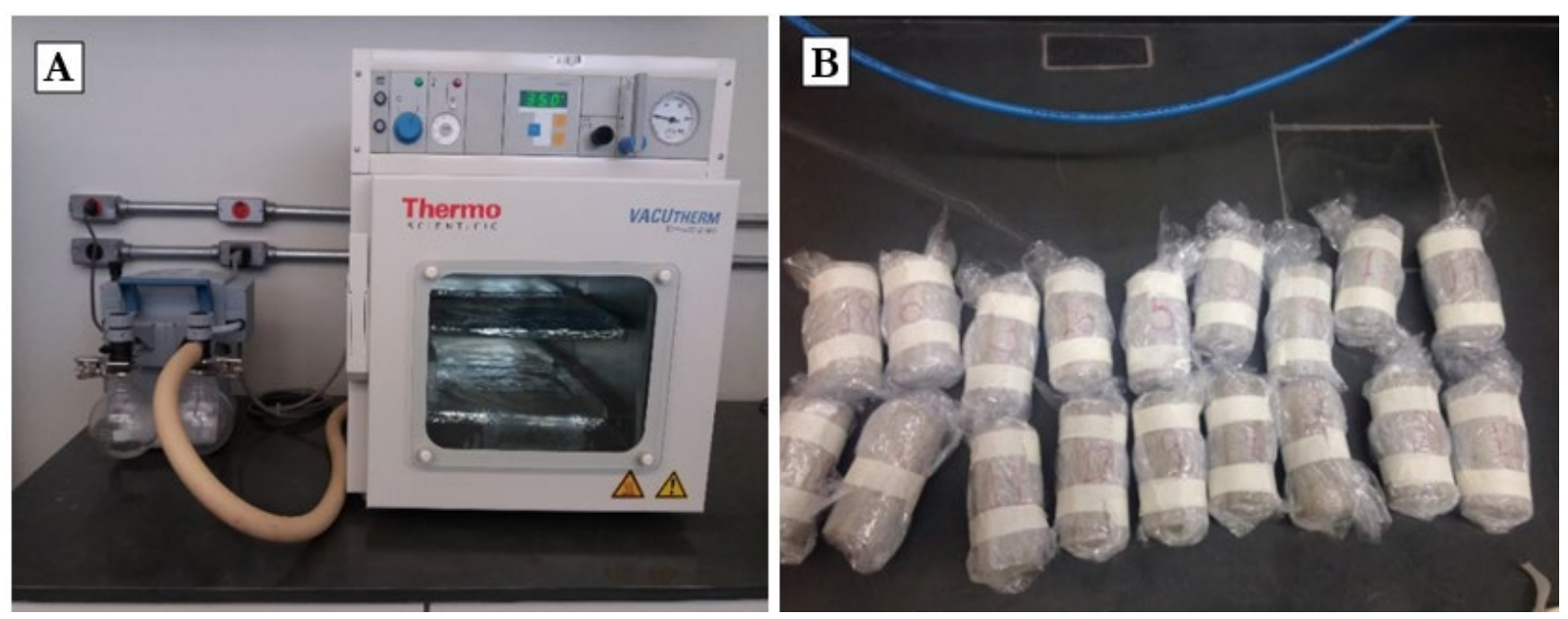

Figure 1. Stages of the precondition adopted: $1^{\text {a }}$ Stage - vacuum oven (A) and $2^{\text {a }}$ Stage - Samples packaged in a plastic film (B).

\section{Accelerated carbonation}

As carbonation in the natural environment happens slowly, the specimens were placed in an accelerated carbonation chamber, model Thermo Scientific SteriCult $\mathrm{CO}_{2}$, with favorable conditions to increase the speed of the process, by controlling the variables that influence it, specifically the $\mathrm{CO}_{2}$ concentration, temperature and relative humidity. In this work, the recommendations of the international standard ISO 1920-12 [20] for hot climates were adopted, which establishes as a test conditions a $\mathrm{CO}_{2}$ concentration equal to $(3.0 \pm 0.5) \%$, a temperature of $(27 \pm 2){ }^{\circ} \mathrm{C}$ and a relative humidity of $(65 \pm 5) \%$. 
The monitoring of the advance of the carbonated thickness was carried out by the colorimetric method, by spraying a solution of phenolphthalein on the surface of the samples. The phenolphthalein solution was prepared as specified by ISO 1920-12 [20], with $1 \mathrm{~g}$ of powdered phenolphthalein dissolved in $70 \mathrm{ml}$ of ethanol and $30 \mathrm{ml}$ of deionized water.

For each of the five carbonation ages evaluated $(0,28,56,70$ and 98 days, whose counting starts after the end of the preconditioning stage), three specimens of each analyzed condition were cut transversely in half of their height, one of the halves being used to evaluate the carbonated thickness through the sprinkling of phenolphthalein solution on the exposed surface. Subsequently, the other half was sawn lengthwise, along the height, to obtain another surface for the evaluation of the carbonation front, also by the colorimetric method (Figure 2). The carbonation depth was read in 16 points, using a digital caliper, with an accuracy of $\pm 0.05 \mathrm{~mm}$.

\section{$\mathbf{A}$}

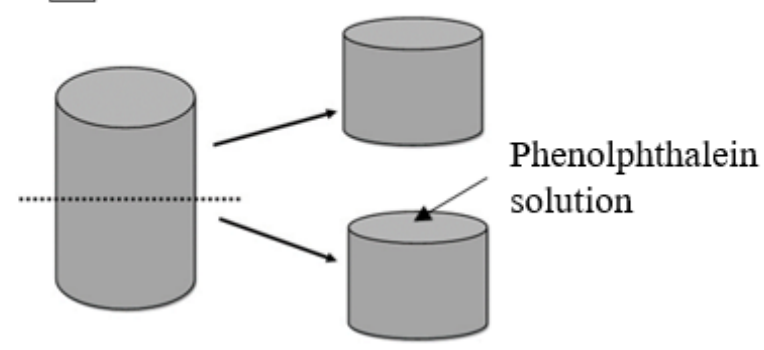

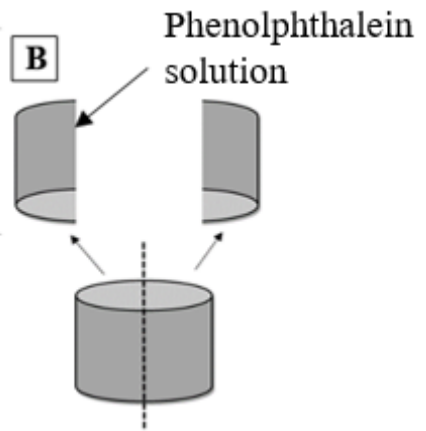

Figure 2. Cutting pattern of samples for measuring carbonated thickness after spraying phenolphthalein solution: transversal cut (A) and longitudinal (B).

\section{Scanning electron microscopy (SEM)}

For the study of the composite microstructure under the four conditions evaluated in this work, the scanning electron microscopy (SEM) technique was used. The equipment used for the test was the FEG - Quanta 200 FEI Scanning Electron Microscope.

Analyses were performed for specimens submitted to accelerated carbonation for 98 days. The samples were extracted from a cross section of a specimen of each consolidation condition, with dimensions approximately $(20 \times 25 \times 3) \mathrm{mm}$. Each of these samples involved both an outer region of the specimens, already carbonated in greater intensity, and an internal region, where carbonation had not yet been detected by the colorimetric method used. Magnifications were performed 40 times to 20,000 times in the samples, generating images using secondary electrons (SE).

\section{RESULTS AND DISCUSSIONS}

The results of the tests, performed as detailed in the previous topic, will be presented below.

\section{Normal consistency index}

The consistency indexes obtained for the two mixtures evaluated in this research, with w/c ratios equals to 0.55 and 0.65 , were $(219 \pm 1) \mathrm{mm}$ and $(288 \pm 2) \mathrm{mm}$, respectively. The results proved that the use of less content of water in the mixture causes a drop in the workability of the mass in the fresh state.

\section{Compressive strength}

The average values of compressive strength, observed at each age, for the four conditions analyzed, can be seen in the graph of Figure 3 and Table 5. The uncertainties of the results presented correspond to the mean absolute deviation (MAD) of the individual results obtained. Table 5 also presents the percentage difference in the compressive strength related to the influence from the variation in the consolidation pattern and the variation of the w/c ratio. 


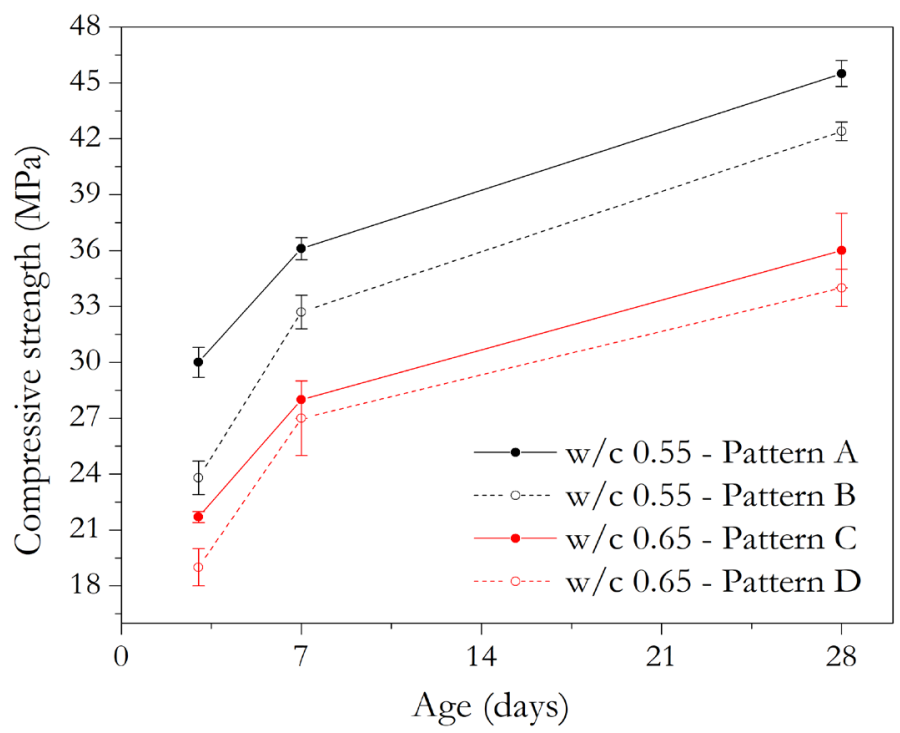

Figure 3. Average compressive strength.

Table 5. Average compressive strength.

\begin{tabular}{|c|c|c|c|c|c|c|c|c|c|c|}
\hline \multirow{2}{*}{$\begin{array}{c}\mathbf{w} / \mathrm{c} \\
\text { ratio }\end{array}$} & \multirow{2}{*}{ Consolidation } & \multicolumn{9}{|c|}{ Compressive strength (MPa) } \\
\hline & & 3 days & Dif. 1 & Dif. 2 & 7 days & Dif. 1 & Dif. 2 & 28 days & Dif. 1 & Dif. 2 \\
\hline \multirow{2}{*}{0.55} & Pattern A & $30.0 \pm 0.8$ & - & - & $36.1 \pm 0.6$ & - & - & $45.5 \pm 0.7$ & - & - \\
\hline & Pattern B & $23.8 \pm 0.9$ & $-21 \%$ & - & $32.7 \pm 0.9$ & $-9 \%$ & - & $42.4 \pm 0.5$ & $-7 \%$ & - \\
\hline \multirow{2}{*}{0.65} & Pattern C & $21.7 \pm 0.3$ & - & $-28 \%$ & $28 \pm 1$ & - & $-22 \%$ & $36 \pm 2$ & - & $-21 \%$ \\
\hline & Pattern D & $19 \pm 1$ & $-12 \%$ & $-20 \%$ & $27 \pm 2$ & $-4 \%$ & $-17 \%$ & $34 \pm 1$ & $-6 \%$ & $-20 \%$ \\
\hline
\end{tabular}

Notes: Dif. 1 is the percentage difference which refers to the influence of the consolidation pattern (comparison between A-B and C-D patterns). Dif. 2 is the percentage difference which refers to the influence of the $\mathrm{w} / \mathrm{c}$ ratio (comparison between A-C and B-D patterns).

As expected, the influence of both the water/cement ratio and the specified consolidation pattern is observed, however, there are differences in behavior over time. The mixtures produced with a w/c ratio equal to 0.65 , regardless of the consolidation pattern, showed results of compressive strength always below the mixtures produced with w/c ratio equal to 0.55 , these being $28 \%$ smaller at 3 days and $21 \%$ lower at 28 days, for mixtures with $\mathrm{A}$ and $\mathrm{C}$ consolidation patterns, showing a reduction in the difference in compressive strength between the mixtures at older ages. As for the less dense mixtures (patterns B and D), there was no great influence on the age of rupture of the specimens in the percentage in which the $\mathrm{D}$ condition was below the B condition, with this difference always remaining around $20 \%$.

When only the influence of the consolidation in the mixtures with the same water/cement ratio was evaluated, it appears that the inferior condition of consolidation caused, in all cases, a decrease in the compressive strengths. The influence of the established consolidation condition was more present, however, in the younger ages and in the mix with the lowest water-cement ratio (w/c equal to 0.55 ). As this mixture presented less workability, it requires a more energetic process to eliminate voids. The results indicate that the lower the consistency index of the mixture, the greater the impacts resulting from failures in the consolidation stage.

It is interesting to note that the harmful effect caused by the unfavorable consolidation conditions introduced in this study, has been mitigated over time, by the advancement of cement hydration in the composite matrix.

The hypothesis test for comparing the four conditions, and between ages, using two-way ANOVA, confirmed that these two factors are significant (under any level of significance greater than 0.01) to explain the variability of compressive strength. The comparisons, two by two, between the four conditions, showed that, except for the comparison between $\mathrm{C}$ and $\mathrm{D}$, all conditions have different mean resistances. The level of global significance used for comparisons two by two was 0.05 . 


\section{Carbonation front advance}

Figure 4 shows the advance of the carbonation front in cylindrical specimens, after 0,28, 56, 70 and 98 days of exposure to the $\mathrm{CO}_{2}$-rich atmosphere of the carbonation chamber. The measurement shown below each image provides the average value of the carbonated thickness, calculated from 16 measurements taken. The uncertainties of the results presented correspond to the mean absolute deviation (MAD) of the individual results obtained.

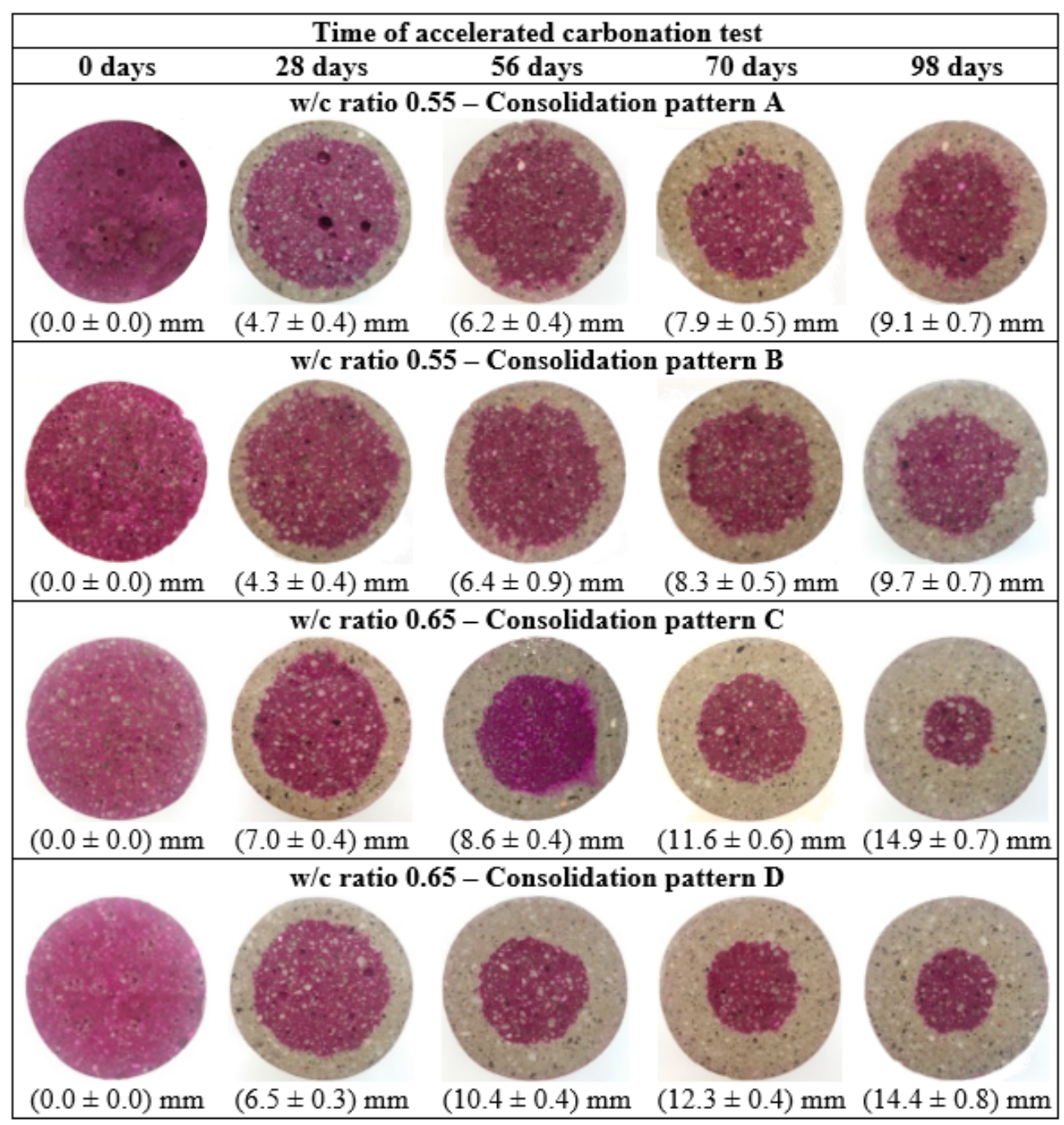

Figure 4. Monitoring the progress of the carbonation front by colorimetric $\mathrm{pH}$ indicator.

From the average value of the carbonated thickness of each sample, shown in Figure 4, and based on Equation 1, it was possible to determine the value of the diffusion coefficient (k), for each of the analyzed mixtures and consolidation conditions. The values obtained are shown in Table 6 . Table 6 also presents the percentage difference in the diffusion coefficient related to the influence from the variation in the consolidation pattern and the variation of the $\mathrm{w} / \mathrm{c}$ ratio. 
Table 6. Diffusion coefficients obtained for each mixture and consolidation condition analyzed.

\begin{tabular}{ccccccc}
\hline w/c ratio Consolidation pattern & $\mathbf{k}\left(\mathbf{m m . d a y s} \mathbf{s}^{-\mathbf{2}}\right)$ & Dif. 1 & Dif. 2 & Model & $\mathbf{r}^{\mathbf{2}}$ \\
\hline \multirow{2}{*}{0.55} & Pattern A & 0.90257 & - & - & $e_{C}=0.90257 \cdot \sqrt{t}$ & 0.99078 \\
\cline { 2 - 7 } & Pattern B & 0.93696 & $+3.8 \%$ & - & $e_{C}=0.93696 \cdot \sqrt{t}$ & 0.97921 \\
\hline \multirow{2}{*}{0.65} & Pattern C & 1.37283 & - & $+52 \%$ & $e_{C}=1.37283 \cdot \sqrt{t}$ & 0.96323 \\
\cline { 2 - 7 } & Pattern D & 1.41938 & $+3.4 \%$ & $+51 \%$ & $e_{C}=1.41938 \cdot \sqrt{t}$ & 0.98935 \\
\hline
\end{tabular}

Notes: Dif. 1 is the percentage difference which refers to the influence of the consolidation pattern (comparison between A-B and C-D patterns). Dif. 2 is the percentage difference which refers to the influence of the w/c ratio (comparison between A-C and B-D patterns).

Figure 5 shows the graphs of the adjusted functions, as well as the average values obtained by measuring the advance of the carbonation front along the accelerated carbonation test.

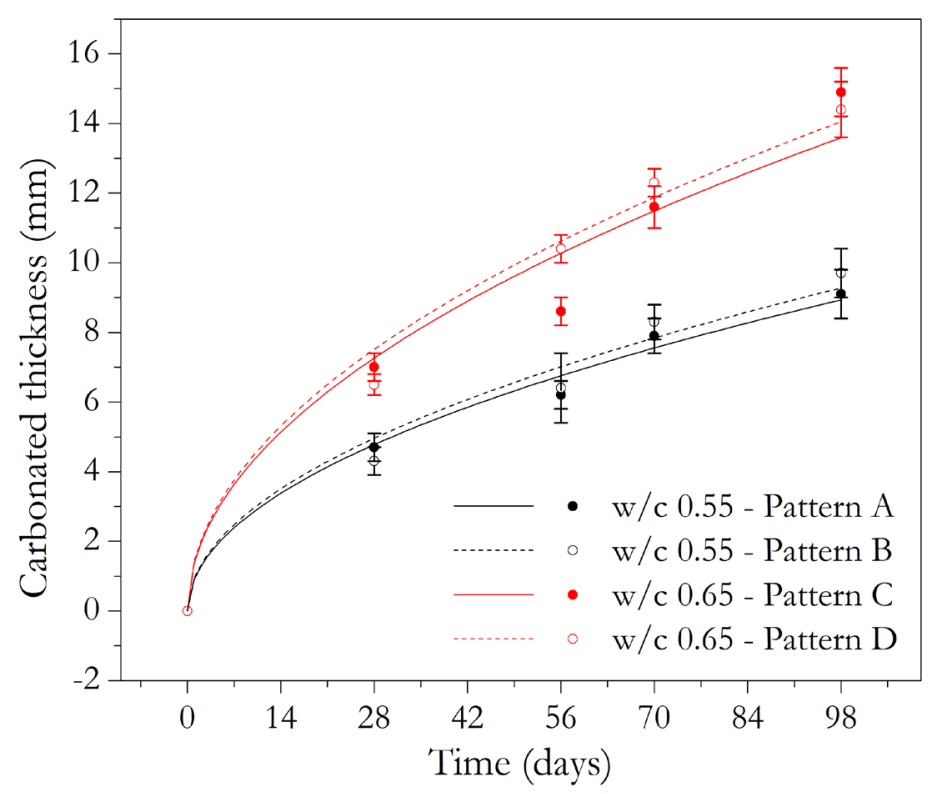

Figure 5. Advance of carbonation front in the samples submitted to the accelerated carbonation test.

There is a great improvement in the performance of the cementitious composite, regarding the advance of the carbonation front, produced by the reduction of the water/cement ratio. The diffusivity constant value obtained for samples with w/c ratio of 0.65 was approximately $50 \%$ higher than for those that were molded with a ratio of 0.55 .

It is also noteworthy that the model used to describe the advance of the carbonation front, provided by Equation 1, was adequate for the conditions analyzed, given that the correlation coefficient $\left(\mathrm{r}^{2}\right)$ of all adjustments was close to 1 .

The hypothesis test for comparing the four conditions, and between ages, using two-way ANOVA, confirmed that these two factors are significant (under any level of significance greater than 0.01) to explain the advance of the carbonation front. The comparisons, two by two, between the four conditions, showed that, except for the comparison between $\mathrm{A}$ and $\mathrm{B}$, all conditions have different mean carbonated thickness. The level of global significance used for comparisons two by two was 0.05 .

It should be noted that what was measured in this work was only the region where the hydrogen potential of the cementitious material was reduced to levels capable of being detected by the $\mathrm{pH}$ colorimetric indicator, and not the presence of carbonic acid $\left(\mathrm{H}_{2} \mathrm{CO}_{3}\right)$ reactions with the mortar alkali. 


\section{Scanning electron microscopy (SEM)}

Through the images generated by the SEM, the microstructure of the samples was evaluated, which allowed some differences to be verified between the four conditions analyzed here and also the differences between the carbonated and non-carbonated regions of the samples.

Figure 6 shows the images generated by SEM for the four consolidation conditions under study with a magnification of 40 times, where the presence of larger pores is observed in the samples with worse consolidation conditions (patterns B and D) when compared to the better dense features (patterns A and C). However, in the images obtained with a magnification of 5,000 times, shown in Figure 7, there is a greater presence of pores, due to the change in consolidation conditions, only for samples produced with a w/c ratio equal to 0.55 . For samples produced with a ratio of $w / c$ equal to 0.65 , it is possible to state only that their void volume is much higher than those observed in samples with $\mathrm{w} / \mathrm{c}$ equal to 0.55 , regardless of the consolidation condition. It can also be said that, only by observing the images (C) and (D) of Figure 7, it is not possible to state that the change in the consolidation process caused a significant variation in the voids volume of the analyzed samples. These findings corroborate to validate the analyses made previously based on the results obtained from compressive strength and resistance to the advance of the carbonation front.
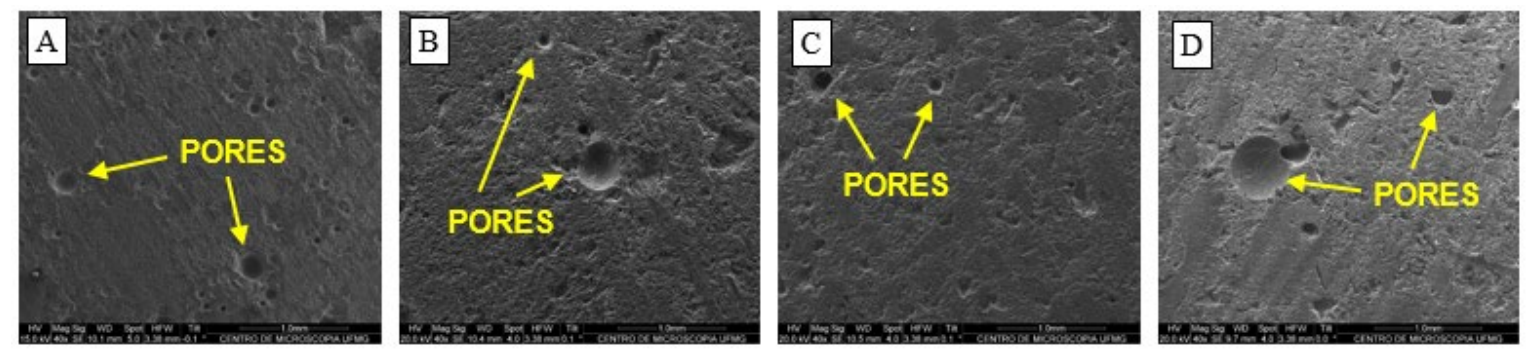

Figure 6. Images generated by SEM (SE) with a magnification of 40 times for the four consolidation conditions: w/c $0.55-$ pattern A (A), w/c 0.55 - pattern B (B), w/c 0.65 - pattern C (C) e w/c 0.65 - pattern D (D).
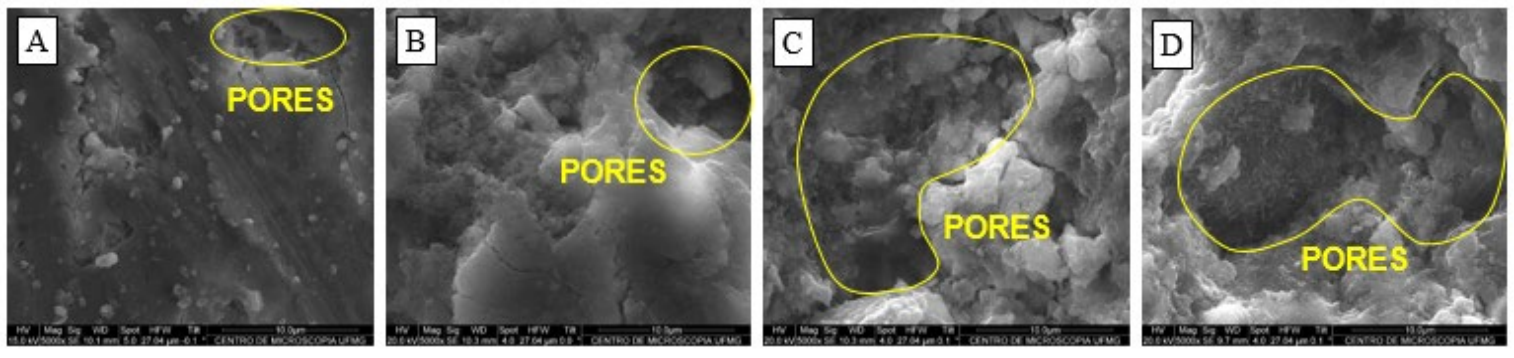

Figure 7. Images generated by SEM (SE) with a magnification of 5,000 times for the four consolidation conditions: w/c $0.55-$ pattern A (A), w/c 0.55 - pattern B (B), w/c 0.65 - pattern C (C) e w/c 0.65 - pattern D (D).

Figure 8 shows the images obtained on the SEM for the consolidation condition B, with a magnification of 20,000 times, for the carbonated and non-carbonated regions of the sample. The images show the occurrence of carbonation reactions, since the products of this reaction can be observed in the carbonated zone of the sample. In this region, it is possible to visualize the precipitation of small crystals, typical of calcium carbonates, aggregated on larger smooth surfaces, characteristic of calcium hydroxide. In the image of the non-carbonated region, the smooth surface of the calcium hydroxide remains without the presence of such incrustations. 

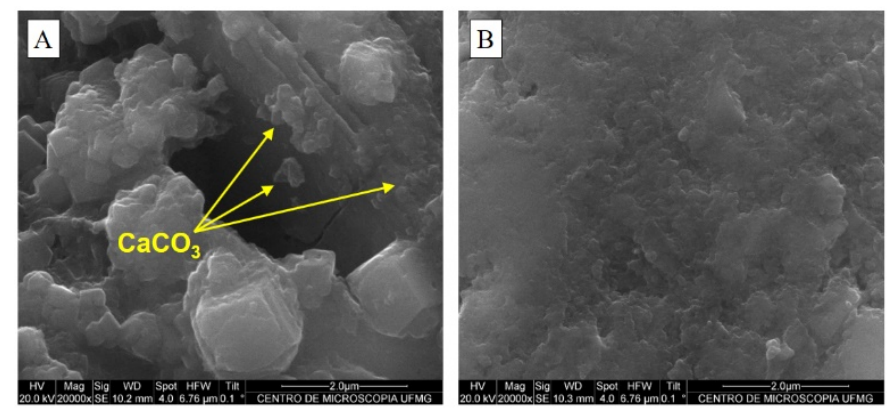

Figure 8. Images generated by SEM (SE) with a magnification of 20,000 times, for the carbonated (A) and non-carbonated (B) regions.

\section{CONCLUSIONS}

The results obtained show the influence of voids on the properties of cementitious composites. The increase in the proportion of water in the mixture and/or the reduction in the quality of the consolidation altered the void structure of the material and, consequently, produced effects on the evaluated properties. The impact on the empty structure of the material must, however, be analyzed not only in terms of the variation caused in its volume, but also in the pattern of its distribution, in its morphology and in its connectivity.

The statistical treatment of the experimental data generated, using two-way analysis of variance (ANOVA) and the Tukey's HSD multiple comparison method, for comparison between the four conditions under study, and between ages, confirmed that such factors are significant (under any significance level greater than 0.01 ) to explain the variability of compressive strength. The influence of the established consolidation condition was more present, however, in the younger ages and in the mix with the lowest water-cement ratio (w/c equal to 0.55 ). The results indicate that the lower the workability of the mixture, the greater the impacts on the compressive strength of the material, resulting from failures in the consolidation stage. The comparisons, two by two, between the four conditions, showed that, except for the comparison between $\mathrm{C}$ and $\mathrm{D}$, all conditions have different mean resistances. The level of global significance used for comparisons two by two was 0.05 . The images obtained by SEM, with an increase of 5,000, corroborate for the validation of such analyses.

It was also observed that the harmful effect on the compressive strength caused by the unfavorable consolidation conditions introduced in this study, was mitigated over time, by the advance of cement hydration in the composite matrix.

Statistical tests indicated that there was no evidence that patterns A and B generated different averages for the carbonation progress. This result shows that despite the reduction in compressive strength observed in pattern $\mathrm{B}$ in relation to pattern A, indicating an increase in the volume of voids incorporated in the samples due to differences in the consolidation process, there was no increase in the connectivity of its open porosity. The other comparisons of average carbonation between standards were all significant at an overall significance level of 0.05 . This demonstrates that the consolidation pattern $\mathrm{D}$, despite not producing a significant variation in the volume of voids capable of causing a variation in the compressive strength tests, as seen in the images (C) and (D) of Figure 7, made its pore network more connected, favoring the advancement of the carbonation front.

\section{ACKNOWLEDGEMENTS}

The authors would like to thank FAPEMIG and CAPES for the financial support given for structuring the laboratory over the years, LafargeHolcim for the support and supply of the cement used in this research and the Laboratory of Cementitious Materials at the UFMG School of Engineering for providing the necessary infrastructure to testing.

\section{REFERENCES}

[1] E. P. Figueiredo, "Efeitos da carbonatação e de cloretos no concreto," in Concreto: Ensino, Pesquisa e Realizações, G. C. Isaia, Ed., São Paulo: IBRACON, 2005, vol. 2, ch. 27, pp. 829-855.

[2] O. Cascudo and H. Carasek, "Ação da carbonatação no concreto," in Concreto: Ensino, Pesquisa e Realizações, G. C. Isaia, Ed., São Paulo: IBRACON, 2011, vol. 1, ch. 24, pp. 849-885. 
[3] M. Hamada, "Neutralization of concrete and corrosion of reinforcing steel: properties of cement paste and concrete," in Proc. Fifth Int. Symp. Chem. Cem., Tokio, Part III, vol. III, Dec. 1969, pp. 343-369.

[4] C. Pauletti, "Estimativa da carbonatação natural de materiais cimentícios a partir de ensaios acelerados e de modelos de predição," Ph.D. dissertation, Esc. Eng., UFRGS, Porto Alegre, RS, 2009.

[5] B. Šavija and M. Lukovic, "Carbonation of cement paste: understanding, challenges, and opportunities," Constr. Build. Mater., vol. 117, pp. 285-301, Aug 2016, http://dx.doi.org/10.1016/j.conbuildmat.2016.04.138.

[6] V. G. Papadakis, C. G. Vayenas, and M. N. Fardis, "A reaction engineering approach to the problem of concrete carbonation," AIChE J., vol. 35, no. 10, pp. 1639-1650, Oct 1989, http://dx.doi.org/10.1002/aic.690351008.

[7] V. Shah, K. Scrivener, B. Bhattacharjee, and S. Bishnoi, "Changes in microstructure characteristics of cement paste on carbonation," Cement Concr. Res., vol. 109, pp. 184-197, Apr 2018, http://dx.doi.org/10.1016/j.cemconres.2018.04.016.

[8] A. M. Neville, Propriedades do Concreto, R. A. Cremonini, Transl., 5. ed. Porto Alegre: Bookman, 2016.

[9] H. Pourbaix, Atlas of Electrochemical Equilibria in Aqueous Solutions. Oxford: Pergamon Press, 1966.

[10] A. Meyer, "Investigations on the carbonation of concrete," in Proc. Fifth Int. Symp. Chem. Cem., Tokio, Part III, vol. III, Dec. 1969, pp. 394-401.

[11] A. M. Neville and J. J. Brooks, Tecnologia do Concreto, 2. ed. Porto Alegre: Bookman, 2013.

[12] American Concrete Institute, Guide for Consolidation of Concrete, ACI 309R-05, 2005.

[13] M. N. Al-Khalaf and M. H. A. Yousif, "Effect of revibration on the stability and compactibility of concrete," Cement Concr. Res., vol. 15, no. 5, pp. 842-848, 1985, http://dx.doi.org/10.1016/0008-8846(85)90151-6.

[14] T. Gonen and S. Yazicioglu, "The influence of compaction pores on sorptivity and carbonation of concrete," Constr. Build. Mater., vol. 21, no. 5, pp. 1040-1045, 2007, http://dx.doi.org/10.1016/j.conbuildmat.2006.02.010.

[15] X. Gao, J. Zhang, and Y. Su, "Influence of vibration-induced segregation on mechanical property and chloride ion permeability of concrete with variable rheological performance," Constr. Build. Mater., vol. 194, pp. 32-41, 2019, http://dx.doi.org/10.1016/j.conbuildmat.2018.11.019.

[16] Associação Brasileira de Normas Técnicas, Cimento Portland - Determinação da Resistência à Compressão, NBR 7215, 2019.

[17] Associação Brasileira de Normas Técnicas, Cimento Portland-Requisitos, NBR 16697, 2018.

[18] Associação Brasileira de Normas Técnicas, Areia Normal para Ensaio de Cimento - Especificação, NBR 7214, 2015.

[19] Associação Brasileira de Normas Técnicas, Projetos de Estruturas de Concreto - Procedimento, NBR 6118, 2014.

[20] International Organization For Standardization, Testing of Concrete - Part 12: Determination of the Carbonation Resistance of Concrete - Accelerated Carbonation Method, ISO 1920-12, 2015.

[21] F. G. Silva, P. Helene, P. Castro-Borges, and J. B. L. Liborio, "Sources of variations when comparing concrete carbonation results," J. Mater. Civ. Eng., vol. 21, no. 7, pp. 333-342, Jun 2009, http://dx.doi.org/10.1061/(asce)0899-1561(2009)21:7(333).

[22] P. C. Cordeiro, R. G. R. Silva, L. A. B. A. Ferreira, A. G. Magalhães, F. C. França, and E. V. M. Carrasco, "Estudo comparativo entre diferentes tipos de cura e sua influência no avanço da carbonatação em compósitos cimentícios," in $59^{\circ} C B C-I B R A C O N$, Bento Gonçalves, RS, Oct.-Nov., 2017.

Author's contributions: RGRS: methodology, data curation, formal analysis, writing; AGM: conceptualization, funding acquisition, supervision, writing, methodology, formal analysis; CAC: methodology, data curation, formal analysis; IRS: data curation, formal analysis, writing.

Editors: Bernardo Tutikian, Guilherme Aris Parsekian. 